\title{
Values of serum LDL and PCT levels in evaluating the condition and prognosis of acute cerebral infarction
}

\author{
XIANLIANG MENG ${ }^{1}$, RENYING WEN ${ }^{2}$ and XIAO $\mathrm{LI}^{3}$ \\ ${ }^{1}$ Department of Neurology, Binzhou City Center Hospital; \\ ${ }^{2}$ Department of Internal Medicine, People's Hospital of Huimin County; \\ ${ }^{3}$ Department of Rehabilitation, Binzhou City Center Hospital, Binzhou, Shandong 251700, P.R. China
}

Received October 12, 2017; Accepted July 19, 2018

DOI: $10.3892 / \mathrm{etm} .2018 .6522$

\begin{abstract}
Values of low density lipoprotein (LDL) and procalcitonin (PCT) levels in evaluating the condition and prognosis of patients with acute cerebral infarction (ACI) were investigated. According to the volume of cerebral infarction, 150 patients with ACI (observation group) were divided into the mild infarction group $(\mathrm{n}=50)$, moderate infarction group $(\mathrm{n}=50)$, and severe infarction group $(\mathrm{n}=50)$. Besides, another 50 healthy subjects were enrolled during the same period as the control group. The levels of serum LDL and PCT on admission and at the 1st, 3rd, 7th and 10th day after treatment were detected, which were compared with those in the control group. Ten days after treatment, patients were divided into two groups, the effective group and non-effective group, based on the clinical efficacy. The differences in LDL and PCT levels were compared between the two groups. After 1 month, the clinical efficacy was evaluated again, and the correlations of LDL and PCT levels with prognosis were analyzed. The levels of serum LDL and PCT in the observation group 1 day after admission were higher than those in the control group $(\mathrm{P}<0.05)$, which reached the peak at the 3rd day and continuously declined after the 7th day. The LDL and PCT levels had statistically significant differences between the effective group and non-effective group $(\mathrm{P}<0.05)$. Pearson's correlation analysis showed that the serum LDL and PCT levels in acute phase were negatively correlated with the National Institutes of Health Stroke Scale (NIHSS) score after 1 month of treatment $(\mathrm{P}<0.05)$. The dynamic monitoring of serum LDL and PCT levels in ACI patients can help evaluate the condition and prognosis of patients.
\end{abstract}

Correspondence to: Dr Xianliang Meng, Department of Neurology, Binzhou City Center Hospital, Ward 2, 108 Huancheng Nan Road, Binzhou, Shandong 251700, P.R. China

E-mail: msb10m@163.com

Key words: low density lipoprotein, procalcitonin, acute cerebral infarction, disease condition, prognosis

\section{Introduction}

Cerebrovascular diseases have become major factors harming the life and health of the middle-aged and elderly in China, among which the acute cerebral infarction (ACI), characterized by high disability, mortality and recurrence rates, is the most common type (1).

Scholars believe that the main pathogenesis of ACI is the deposition of lipid, mainly low density lipoprotein (LDL), in the cerebral arterial wall, arterial intimal thickening, luminal stenosis, and blood supply disturbance in the corresponding brain tissues, leading to ischemia-hypoxia necrosis (2). Atherosclerosis can also be seen as a kind of chronic inflammatory injury involving adaptive immunity (3-5). Therefore, the inflammatory response markers also play an important role in ACI (6). Procalcitonin (PCT) is a more sensitive serum inflammatory factor, which is associated with the risk of ACI (7). The accurate judgement of condition and prediction of development play key roles in the prevention and treatment of ACI (8). Moreover, timely intervention and appropriate treatment measures based on the correct judgement will greatly improve the prognosis of patients (9).

Values of LDL and PCT levels in evaluating the condition and prognosis of patients with ACI were investigated. Pearson's correlation analysis revealed that the serum LDL and PCT levels in acute phase were negatively correlated with the National Institutes of Health Stroke Scale (NIHSS) score after 1 month of treatment $(\mathrm{P}<0.05)$. Thus, the dynamic monitoring of serum LDL and PCT levels in ACI patients can help evaluate the condition and prognosis of patients.

\section{Patients and methods}

General data. One hundred and fifty patients diagnosed with ACI in Binzhou City Center Hospital (Binzhou, China) from February 2017 to August 2017 were selected as the observation group, and another 50 healthy subjects were selected during the same period as the control group. The differences in sex and age were not statistically significant between the two groups (Table I). According to the volume of cerebral infarction, the observation group was divided into three groups: the mild infarction group $(n=50)$, the moderate infarction group $(n=50)$ and the severe infarction group $(n=50)$. There were no statistically significant 
differences in the age and sex among the three groups (Table II), and the results were comparable. Inclusion criteria were: i) patients aged 18-81 years of either sex; ii) patients meeting the diagnostic criteria for ACI developed by the Fourth National Conference on Cerebrovascular Disease with the time from onset to admission of $<3$ days $(10,11)$; iii) patients whose infarction location could be clearly defined via head computed tomography (CT) or magnetic resonance imaging (MRI) scan with a single lesion; and iv) patients who agreed and signed the informed consent of clinical trial. Exclusion criteria were: i) patients with a history of cerebral infarction or coronary heart disease who received recent thrombolytic therapy; ii) patients with brain metastasis of malignant tumor; iii) patients with autoimmune diseases; iv) patients complicated by severe disorders in other organs; v) patients with infection or had received recent trauma surgery; and vi) patients who had received recently immune or biological agents. The study was approved by the Ethics Committee of Binzhou City Center Hospital.

Evaluation criteria. i) Evaluation of infarction volume using Coniglobus formula (11): Cerebral infarction volume $\mathrm{V}\left(\mathrm{cm}^{3}\right)=$ a x b x c x $\pi / 6$, where a, long diameter of infarction focus (cm); $\mathrm{b}$, short diameter of infarction focus (cm); c, layer spacing of infarction focus (cm). ii) Evaluation of clinical efficacy. The clinical efficacy was divided into five grades according to the NIHSS score (Table III). The patients with progress, remarkable progress and basic recovery were classified as effective group, while those with other grades were classified as the non-effective group. NIHSS scores were measured 10 days after treatment.

Research methods. Fasting elbow venous blood $(3 \mathrm{ml})$ was drawn from patients in the observation group at approximately 6 a.m. at the 1st, 3rd, 7th and 10th days after admission, while $3 \mathrm{ml}$ fasting elbow venous blood was drawn from patients in control group in the early morning on the day of physical examination. The serum PCT and LDL were detected via enzyme-linked immunosorbent assay (ELISA). The normal reference ranges are as follows: PCT $<0.5 \mathrm{ng} / \mathrm{ml}$ and LDL $<3.36 \mathrm{mmol} / \mathrm{l}$. After 10 days, patients were divided into the effective group and non-effective group based on the clinical efficacy. After 1 month, the clinical efficacy was evaluated again, and the correlations of LDL and PCT levels with NIHSS score 1 month after treatment were analyzed.

Statistical analysis. Statistical analysis was performed using Statistical Product and Service Solutions (SPSS) 21.0 software (Cabit Information Technology Co., Ltd., Shanghai, China). The measurement data in normal distribution were presented as mean \pm standard deviation. The t-test was used for the comparison of data with homogeneous variance, and one-way analysis of variance (ANOVA) was used for the comparison among groups. The Mann-Whitney U test was used for the comparison of data in abnormal distribution or with heterogeneous variance. The Kruskal Wallis $\mathrm{H}$ test was used for the comparison among groups, and the repeated measures ANOVA used for the comparison at different time-points within the group. $\mathrm{RxC}$ Chi-square test was used for the comparison of enumeration data. The correlations of LDL and PCT with treatment time were analyzed using linear correlation analysis. $\mathrm{P}<0.05$ was conside red to indicate a statistically significant difference.
Table I. Comparison of general data between the two groups.

\begin{tabular}{lcccc}
\hline $\begin{array}{l}\text { General } \\
\text { data }\end{array}$ & $\begin{array}{c}\text { Observation } \\
\text { group }\end{array}$ & $\begin{array}{c}\text { Control } \\
\text { group }\end{array}$ & $\chi^{2}$ & P-value \\
\hline $\mathrm{n}$ & 150 & 50 & & \\
Sex $(\%)$ & & & & \\
Male & $88(58.67 \%)$ & $28(56.00 \%)$ & 3.06 & 0.36 \\
Female & $62(41.33 \%)$ & $22(44.00 \%)$ & 3.06 & 0.36 \\
Age (years) & & & & 0.29 \\
$<50$ & $20(13.33 \%)$ & $8(16.00 \%)$ & 3.12 & 0.38 \\
$50-70$ & $98(65.33 \%)$ & $33(66.00 \%)$ & 3.02 & 0.39 \\
$>70$ & $32(21.33 \%)$ & $9(18.00 \%)$ & 2.79 & 0.28 \\
BMI $\left(\mathrm{kg} / \mathrm{m}^{2}\right)$ & $25.05 \pm 3.24$ & $24.77 \pm 2.98$ & $t=1.012$ & 0.59 \\
\hline
\end{tabular}

BMI, body mass index.

\section{Results}

Comparison of PCT and LDL levels 1 day after admission between the observation group and control group. The levels of serum PCT and LDL in the observation group at the 1st day after admission were significantly higher than those in the control group, and the differences were statistically significant $(\mathrm{P}<0.05)$ (Table IV).

Levels of serum LDL and PCT in observation group at the 1st, $3 r d$, 7th and 10th day after admission. The levels of serum LDL and PCT in observation group at the 1st day after admission were $6.98 \pm 0.61 \mathrm{ng} / \mathrm{ml}$ and $1.28 \pm 0.52 \mathrm{mmol} / \mathrm{l}$ respectively, reached the peak at the 3rd day, continuously declined after the 7th day and got close to the normal ranges at the 10th day (Fig. 1). The levels in each group were compared with those at the previous time-point, and the differences were statistically significant $(\mathrm{P}<0.05)$.

Dynamic changes in LDL and PCT levels in the observation group. The levels of serum LDL and PCT at the 1st day after admission in the three groups of ACI patients were significantly higher than those in the control group $(\mathrm{P}<0.05)$, which reached the peak at the 3rd day and declined at the 7 th day, but they were still higher than those in the control group $(\mathrm{P}<0.05)$. The levels in each group were compared with those at the previous time-point, and the differences were statistically significant $(\mathrm{P}<0.05)$. The serum LDL and PCT levels in the three groups showed increasing trends with the increase of infarction volume, and the differences were statistically significant $(\mathrm{P}<0.05)$ (Table $\mathrm{V})$, suggesting that LDL and PCT levels are related to the severity of disease.

Correlations of LDL and PCT levels with curative effect. After 10 days of treatment, there were 121 out of 150 ACI patients $(80.67 \%)$ in the effective group and 29 patients $(19.33 \%)$ in the non-effective group (Table VI). The LDL and PCT levels in the effective group were lower than those in the non-effective group, and there were statistically significant differences $(\mathrm{P}<0.05)$, suggesting that the lower the LDL and PCT levels are, the better the curative effect may be. 
Table II. Comparison of general data among the three groups in the observation group.

\begin{tabular}{|c|c|c|c|c|c|}
\hline General data & Mild infarction group & Moderate infarction group & Severe infarction group & $\chi^{2}$ & P-value \\
\hline $\mathrm{n}$ & 50 & 50 & 50 & & \\
\hline \multicolumn{6}{|l|}{$\operatorname{Sex}(\%)$} \\
\hline Male & $28(56.00 \%)$ & $24(48.00 \%)$ & $27(54.00 \%)$ & 3.01 & 0.44 \\
\hline Female & $22(44.00 \%)$ & $26(52.00 \%)$ & $23(46.00 \%)$ & 3.01 & 0.44 \\
\hline \multicolumn{6}{|l|}{ Age (years) } \\
\hline$<50$ & $6(12.00 \%)$ & $8(16.00 \%)$ & $9(18.00 \%)$ & 2.68 & 0.35 \\
\hline $50-70$ & $38(76.00 \%)$ & $35(70.00 \%)$ & $31(62.00 \%)$ & 2.88 & 0.37 \\
\hline$>70$ & $6(12.00 \%)$ & $7(14.00 \%)$ & $10(20.00 \%)$ & 2.57 & 0.31 \\
\hline BMI $\left(\mathrm{kg} / \mathrm{m}^{2}\right)$ & $28.12 \pm 3.22$ & $23.29 \pm 4.46$ & $25.47 \pm 2.29$ & $t=1.001$ & 0.96 \\
\hline
\end{tabular}

BMI, body mass index.

Table III. NIHSS score.

\begin{tabular}{lccccc}
\hline Item & Progress & Remarkable progress & Basic recovery & No change & Aggravation \\
\hline NIHSS score & Reduced by 18-45\% & Reduced by $46-89 \%$ & Reduced by $90-100 \%$ & Fluctuation of $<18 \% \quad$ Increase of $\geq 18 \%$ \\
\hline
\end{tabular}

NIHSS, National Institutes of Health Stroke Scale.

Table IV. Comparison of PCT (ng/ml) and LDL levels (mmol/l) at 1 day after admission between the observation group and control group.

\begin{tabular}{lcccc}
\hline Items & $\begin{array}{c}\text { Observation } \\
\text { group }\end{array}$ & $\begin{array}{c}\text { Control } \\
\text { group }\end{array}$ & t value & P-value \\
\hline PCT $(\mathrm{ng} / \mathrm{ml})$ & $1.28 \pm 0.52$ & $0.24 \pm 0.11$ & 0.014 & 0.02 \\
LDL (mmol/l) & $6.98 \pm 0.61$ & $3.35 \pm 0.77$ & 0.020 & 0.04 \\
\hline
\end{tabular}

PCT, procalcitonin; LDL, low density lipoprotein.

Correlation of LDL and PCT levels with prognosis. As seen in Table VII the linear correlation analysis showed that the PCT levels were negatively correlated with NIHSS score $(\mathrm{r}=-1.38$, $\mathrm{P}<0.05)$; LDL was negatively correlated with NIHSS score $(\mathrm{r}=-0.61, \mathrm{P}<0.05)$ (Figs. 1 and 2).

\section{Discussion}

ACI has a high incidence rate in the elderly in China. If there is no timely and effective treatment, the prognosis will be poor and the patients' life, health and life quality later will also be seriously threatened. Its incidence is closely related to the lipid deposition and inflammatory response (12).

In recent years, many studies $(13,14)$ have pointed out that the inflammatory response has an extremely close correlation with atherosclerosis, and they interact with each other, exacerbating brain damage. First, the inflammatory response, as a starting link, can cause changes in the brain arterial plaque and thrombosis.

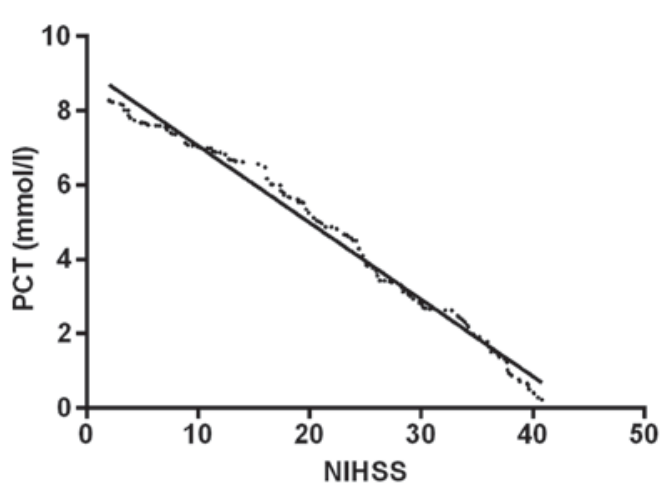

Figure 1. Correlation analysis between PCT and treatment time. PCT level was negatively correlated with NIHSS score by linear correlation analysis. $(\mathrm{r}=-0.61, \mathrm{P}<0.05)$. PCT, procalcitonin; NIHSS, National Institutes of Health Stroke Scale.

Then, when plaque rupture occurs in ACI patients, a large number of inflammatory cells are released, which aggravates the cerebral ischemic injury, although the inflammatory response is inhibited and the damaged tissue repair is promoted. Therefore, the changes in serum inflammatory indexes are important in evaluating the development and prognosis of disease.

PCT is an inflammatory index with a high sensitivity and specificity $(15,16)$, whose content can gradually increase and reach the peak $2-3 \mathrm{~h}$ after inflammatory response, so it has a high value in early diagnosis (17). The increasing trend is associated with the severity of disease, suggesting that PCT may be involved in the pathogenesis as the inflammatory mediator (18). This is also consistent with the results in this study. It was found that the PCT level in ACI patients was significantly higher than that in the normal control group, and it was increased along with the 
Table V. Dynamic changes in LDL and PCT levels in observation group.

\begin{tabular}{|c|c|c|c|c|c|c|}
\hline Items & $\begin{array}{l}\text { Treatment } \\
\text { time (day) }\end{array}$ & $\begin{array}{l}\text { Mild infarction } \\
\text { group }(n=50)\end{array}$ & $\begin{array}{l}\text { Moderate infarction } \\
\text { group }(n=50)\end{array}$ & $\begin{array}{l}\text { Severe infarction } \\
\text { group }(\mathrm{n}=50)\end{array}$ & F-value & P-value \\
\hline \multirow[t]{4}{*}{$\mathrm{LDL}(\mathrm{ng} / \mathrm{ml})$} & 1 & $2.39 \pm 0.53$ & $7.17 \pm 1.16$ & $10.02 \pm 2.29$ & 2.12 & $<0.05^{\mathrm{a}}$ \\
\hline & 3 & $6.72 \pm 0.42$ & $12.39 \pm 1.04$ & $22.04 \pm 2.16$ & 2.34 & $<0.05^{\mathrm{a}}$ \\
\hline & 7 & $5.43 \pm 0.69$ & $8.91 \pm 1.37$ & $11.44 \pm 1.49$ & 2.76 & $<0.05^{\mathrm{a}}$ \\
\hline & 10 & $1.23 \pm 0.62$ & $4.41 \pm 1.66$ & $7.17 \pm 1.31$ & 2.44 & $<0.05^{\mathrm{a}}$ \\
\hline F-value & & 2.22 & 2.15 & 2.57 & & \\
\hline P-value & & $<0.05^{\mathrm{b}}$ & $<0.05^{\mathrm{b}}$ & $<0.05^{\mathrm{b}}$ & & \\
\hline \multirow[t]{4}{*}{ PCT (mmol/l) } & 1 & $0.27 \pm 0.07$ & $1.76 \pm 0.12$ & $2.55 \pm 0.43$ & 2.45 & $<0.05^{\mathrm{c}}$ \\
\hline & 3 & $3.47 \pm 0.53$ & $4.92 \pm 1.28$ & $8.38 \pm 1.95$ & 2.53 & $<0.05^{\mathrm{c}}$ \\
\hline & 7 & $0.24 \pm 0.08$ & $1.98 \pm 0.17$ & $3.74 \pm 0.51$ & 2.12 & $<0.05^{\mathrm{c}}$ \\
\hline & 10 & $0.13 \pm 0.05$ & $1.06 \pm 0.09$ & $2.01 \pm 0.11$ & 2.34 & $<0.05^{\mathrm{c}}$ \\
\hline \multicolumn{7}{|l|}{ F-value } \\
\hline P-value & & $<0.05^{\mathrm{d}}$ & $<0.05^{\mathrm{d}}$ & $<0.05^{\mathrm{d}}$ & & \\
\hline
\end{tabular}

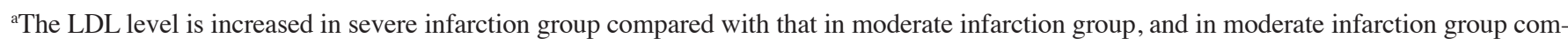

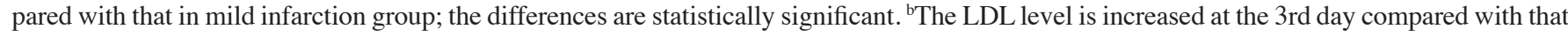
at the 1st day, at the 5th day compared with that at the 1st day, and at the 7th day compared with that at the 5th day. ${ }^{\circ}$ The PCT level is increased in severe infarction group compared with that in moderate infarction group, and in moderate infarction group compared with that in mild infarction group; the differences are statistically significant. ${ }^{\mathrm{d}}$ The PCT level is increased at the 3rd day compared with that at the 1 st day, at the 5th day compared with that at the 1st day and at the 7th day compared with that at the 5th day. LDL, low density lipoprotein; PCT, procalcitonin.

Table VI. Correlation of LDL and PCT levels with curative effect (mean \pm standard deviation).

\begin{tabular}{lcccc}
\hline Groups & $\begin{array}{c}\text { Effective } \\
\text { group }\end{array}$ & $\begin{array}{c}\text { Non-effective } \\
\text { group }\end{array}$ & $\mathrm{t} / \chi^{2}$ & P-value \\
\hline $\mathrm{n}(\%)$ & $121(80.67)$ & $29(19.33)$ & 2.68 & 0.012 \\
Age (years) & $50.34 \pm 13.47$ & $67.39 \pm 11.83$ & 1.33 & 0.27 \\
LDL (mmol/l) & $5.04 \pm 1.27$ & $13.32 \pm 3.13$ & 2.84 & 0.01 \\
PCT (ng/ml) & $1.13 \pm 0.47$ & $5.74 \pm 2.48$ & 2.52 & 0.03 \\
\hline
\end{tabular}

LDL, low density lipoprotein; PCT, procalcitonin.

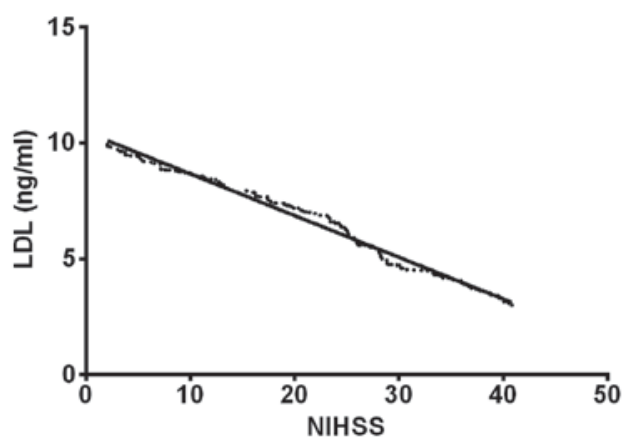

Figure 2. The correlation analysis between LDL and treatment time. LDL was negatively correlated with NIHSS score by linear correlation analysis $(r=-1.38, P<0.05)$. LDL, low density lipoprotein; NIHSS, National Institutes of Health Stroke Scale.

increased degree of infarction. Kumral et al (19) pointed out that controlling the LDL level can effectively improve the prognosis of ACI patients, which is also consistent with our findings. LDL
Table VII. Correlation of LDL and PCT levels with prognosis (mean \pm standard deviation).

\begin{tabular}{lcc}
\hline & \multicolumn{2}{c}{ NIHSS score } \\
\cline { 2 - 3 } Indexes & $\mathrm{r}$ & P-value \\
\hline LDL & & \\
1st day after treatment & 0.356 & 0.028 \\
3rd day after treatment & 0.533 & 0.001 \\
7th day after treatment & 0.278 & 0.144 \\
10th day after treatment & 0.126 & 0.123 \\
PCT & & \\
1st day after treatment & 0.472 & 0.004 \\
3rd day after treatment & 0.701 & 0.027 \\
7th day after treatment & 0.413 & 0.232 \\
10th day after treatment & 0.207 & 0.204 \\
\hline
\end{tabular}

LDL, low density lipoprotein; PCT, procalcitonin; NIHSS, National Institutes of Health Stroke Scale.

is the main carrier of cholesterol in the blood, which consists of approximately 1,500 cholesterol ester molecules. It was found that the LDL level in ACI patients was increased, along with the increased degree of infarction, suggesting that LDL and ACI are closely correlated. Therefore, the effective control of the LDL level can improve the prognosis $(20,21)$.

The linear correlation analysis was used to analyze the correlations of LDL and PCT levels with prognosis, and the results showed that the serum LDL and PCT levels were negatively correlated with the NIHSS score, suggesting that LDL and PCT levels can be used as a cure index for ACI, and 
can be used to monitor the recovery of patients. However, the serum LDL and PCT levels had no significant correlations with prognosis after the 7th day, possibly because the LDL and PCT levels gradually returned to normal after treatment when not in the acute phase. After 1 month, the clinical efficacy was evaluated; the number of patients in effective group $(n=121$, $80.67 \%$ ) was significantly larger than that in the non-effective group ( $n=29,19.33 \%$ ), so the disease was slowly improved. The overall LDL and PCT levels slowly returned to normal.

There were limitations in the experimental conditions, such as the small sample base number, short experimental period and lack of large data support. In order to achieve the best experimental results, we will increase the base number of the research object in the future, and carry out longer follow-up of the patients.

In conclusion, the serum LDL and PCT levels in ACI patients are positively correlated with the disease degree and negatively correlated with NIHSS scores. The dynamic monitoring is helpful in judging the condition and evaluating the prognosis of the disease.

\section{Acknowledgements}

Not applicable.

\section{Funding}

No funding was received.

\section{Availability of data and materials}

The datasets used and/or analyzed during the present study are available from the corresponding author on reasonable request.

\section{Authors' contributions}

XM and RW conceived and designed the study, and drafted the manuscript. XM, RW and XL collected, analyzed and interpreted the experiment data, and revised the manuscript critically for important intellectual content. All authors read and approved the final manuscript.

\section{Ethics approval and consent to participate}

The study was approved by the Ethics Committee of Binzhou City Center Hospital (Binzhou, China). Signed informed consents were obtained from the patients or the guardians.

\section{Patient consent for publication}

Not applicable.

\section{Competing interests}

The authors declare that they have no competing interests.

\section{References}

1. Camerlingo M, Valente L, Tognozzi M, Beretta GL, Moschini L and Cesana BM: C-reactive protein levels in the first three hours after acute cerebral infarction. Int J Neurosci 121: 65-68, 2011.
2. Zhang JY, Liu B, Wang YN, Zhang WN and Wang FJ: Effect of rosuvastatin on OX40L and PPAR- $\gamma$ expression in human umbilical vein endothelial cells and atherosclerotic cerebral infarction patients. J Mol Neurosci 52: 261-268, 2014.

3. Antunes RF, Kaski JC and Dumitriu IE: The role of costimulatory receptors of the tumour necrosis factor receptor family in atherosclerosis. J Biomed Biotechnol 2012: 464532, 2012.

4. Kamel $\mathrm{H}$ and Iadecola C: Brain-immune interactions and ischemic stroke: Clinical implications. Arch Neurol 69: 576-581, 2012.

5. Tsai JZ, Peng SJ, Chen YW, Wang KW, Li CH, Wang JY, Chen CJ, Lin HJ, Smith EE, Wu HK, et al: Automated segmentation and quantification of white matter hyperintensities in acute ischemic stroke patients with cerebral infarction. PLoS One 9: e104011, 2014

6. Tuttolomondo A, Di Raimondo D, Pecoraro R, Arnao V, Pinto A and Licata G: Inflammation in ischemic stroke subtypes. Curr Pharm Des 18: 4289-4310, 2012.

7. Lavrentieva A, Papadopoulou S, Kioumis J, Kaimakamis E and Bitzani M: PCT as a diagnostic and prognostic tool in burn patients. Whether time course has a role in monitoring sepsis treatment. Burns 38: 356-363, 2012.

8. Williams LS, Ghose SS and Swindle RW: Depression and other mental health diagnoses increase mortality risk after ischemic stroke. Am J Psychiatry 161: 1090-1095, 2004.

9. Zhang F, Li X, Dong Q, Wang Y and Zhang H: Risk of acute cerebral infarction and plasma asymmetrical dimethylarginine and homocysteine levels: A clinical correlation analysis of Chinese population. J Stroke Cerebrovasc Dis 23: 2225-2232, 2014.

10. Ahmetgjekaj I,Kabashi-Muçaj S, Lascu LC,Kabashi A, Bondari A, Bondari S, Dedushi-Hoti K, Biçaku A and Shatri J: Magnetic resonance imaging criteria for thrombolysis in hyperacute cerebral infarction. Curr Health Sci J 40: 111-115, 2014.

11. Song Y, Li Q, Long L, Zhang N and Liu Y: Asn563Ser polymorphism of CD31/PECAM-1 is associated with atherosclerotic cerebral infarction in a southern Han population. Neuropsychiatr Dis Treat 11: 15-20, 2014.

12. Maida C, Tuttolomondo A, Di Raimondo D, Daidone M and Pinto A: Management of blood pressure and heart rate in patients with acute stroke. Curr Pharm Des 23: 4583-4597, 2017.

13. Khan MM, Motto DG, Lentz SR and Chauhan AK: ADAMTS13 reduces VWF-mediated acute inflammation following focal cerebral ischemia in mice. J Thromb Haemost 10: 1665-1671, 2012.

14. Lambertsen KL, Biber K and Finsen B: Inflammatory cytokines in experimental and human stroke. J Cereb Blood Flow Metab 32: 1677-1698, 2012

15. Zu H, Li Q, Huang P and Wang X: Therapeutic value of blood purification and prognostic utilities of early serum procalcitonin, $\mathrm{C}$ reactive protein, and brain natriuretic peptide levels in severely burned patients with sepsis. Cell Biochem Biophys 72: 259-263, 2015.

16. Dymicka-Piekarska V and Wasiluk A: Procalcitonin (PCT), contemporary indicator of infection and inflammation. Postepy Hig Med Dosw 69: 723-728, 2015 (In Polish).

17. Gao L, Liu X, Zhang D, Xu F, Chen Q, Hong Y, Feng G, Shi Q, Yang $\mathrm{B}$ and $\mathrm{Xu} \mathrm{L}$ : Early diagnosis of bacterial infection in patients with septicopyemia by laboratory analysis of PCT, CRP and IL-6. Exp Ther Med 13: 3479-3483, 2017.

18. Jiao J, Wang M, Zhang J, Shen K, Liao X and Zhou X: Procalcitonin as a diagnostic marker of ventilator-associated pneumonia in cardiac surgery patients. Exp Ther Med 9: 1051-1057, 2015.

19. Kumral E, Evyapan D, Gökçay F, Karaman B and Orman M: Association of baseline dyslipidemia with stroke recurrence within five-years after ischemic stroke. Int J Stroke 9 (Suppl A100): 119-126, 2014.

20. Zhang Z, Ma N, Zheng Y and Zhang L: Association of serum immunoglobulin-G to Porphyromonas gingivalis with acute cerebral infarction in the Chinese population. J Indian Soc Periodontol 19: 628-632, 2015.

21. Feng S: Diabetes and hyperglycemia after cerebral infarction in acute cerebral infarction. Diabetes N World 19: 76-78, 2016 (In Chinese). 